Dossiê

\title{
0 lugar das elites jurídicas: 0 deslocamento territorial dos ministros do STF (1988-2013)
}

Fernando de Castro Fontainha'

Izabel Saenger Nuñez²

Verônica Beviláqua Otero 3

Resumo: Este artigo tem por objetivo analisar os dados referentes ao que chamamos "trajetória geográfica" dos ministros do STF. De início, caberá a reflexão acerca deste marcador social como integrante de uma trajetória que permitiu a ascensão de indivíduos à mais alta corte brasileira. Indagaremos de que forma $o$ deslocamento territorial permite ou viabiliza distinções capazes de melhor identificar traços elitários nos ministros e ex-ministros do STF. Para tanto, explicitaremos com quais dados trabalhamos e como foi feito seu tratamento no sentido da composição cronológica dos deslocamentos de cada um dos ministros. Por fim, tentaremos identificar padrões de deslocamento territorial e as estruturas que os possibilitam, bem como de que forma estes padrões contribuem para a circulação dos mais diferentes tipos de capital, cuja acumulação alça um indivíduo, através da sua trajetória, à condição de membro da elite judiciária brasileira.

Palavras-chave: Trajetória geográfica, elites jurídicas, capital cultural.

1 Instituto de Estudos Sociais e Políticos da Universidade do Estado do Rio de Janeiro (IESP / UERJ) - Rio de Janeiro - Brasil - fontainha.fernando@gmail.com

2 Doutoranda em antropologia na Universidade Federal Fluminense (UFF) - Niterói - Brasil - izabelsn@ gmail.com

3 Bacharel em Direito pela Fundação Getulio Vargas (FGV) - Rio de Janeiro - Brasil - veronicabevilacqua@ hotmail.com 


\section{LEGAL ELITE'S SPOTS: SUPREME COURT JUSTICES (1988-2013) AND TERRITORIAL DISPLACEMENT}

Abstract: This paper analyses data related to the Brazilian Supreme Court Ministers "geographical trajectory". First, we take into consideration this social marker importance as part of the personal feature that allowed individual rise to the Court. After, we inquire how territorial displacement enables or makes his or her distinctions feasible, in order to identify ministers and ex-ministers elite traits. To do so, we explain data we used and how we dealt with it towards chronologically compose each ministers displacement. At last, we try to identify territorial displacement patterns and the structures that make them possible, as well as how this patterns contributed to capital circulation and how accumulate it through his or her path raises the person to the to the status of a Brazilian Judicial Elite's member.

Key-words: Geographical trajectory, cultural capital, legal elites.

\section{0 deslocamento territorial das elites judiciárias brasileiras}

O Supremo, embora seja a mais alta corte brasileira, não deve ser tomado como amálgama das elites judiciárias brasileiras apenas pelo fato de seus membros comporem o Poder Judiciário, ou por ser ele o tribunal de mais alta hierarquia no país. Esta noção, isoladamente, desconsideraria a pluralidade de origens sociais, profissionais, acadêmicas e políticas daqueles que compõem a corte. O STF não é o topo da carreira judiciária no Brasil.

Os indivíduos que compõem a população que se pretende biografar coletivamente têm na pertença ao STF a pluralidade de uma trajetória elitária. Assim, seu deslocamento territorial deve ser entendido - ainda que na sua dimensão estratégica - como traço distintivo de padrões de deslocamento que possibilitaram a alçada a tal posição, e não retrospectivamente, como simples exemplos de carreiras de sucesso.

Entre exigências institucionais, necessidades políticas, círculos familiares e estratégias profissionais, devemos entender o conjunto de deslocamentos geográficos dos ministros como dados referentes às mais diferentes relações e interações, intensificadas pela proximidade física, que compuseram a sua trajetória.

É no conflito entre poderes locais aristocráticos e uma centralidade republicana que se encontra o centro da discussão. A burocratização e profissionalização dos tribunais e a racionalização progressiva das demais profissões jurídicas vão transformar profundamente os padrões de deslocamento das elites judiciárias. 
Na França, Royer (2001), Charle (1989, 1993) e Boigeol (1989) vão situar os novos padrões de deslocamento das elites judiciárias no contexto do desaparecimento da figura do notable local em prol do magistrado republicano. Para os autores, a tradicional nomeação direta de membros das elites das grandes famílias locais é substituída pela institucionalização de novas sociabilidades e formas de acumulação de capital jurídico. Fenômenos como a universalização e interiorização do ensino jurídico, a implementação de um concurso de acesso e a criação de uma escola de formação profissional são fundamentais na profissionalização e burocratização da função judiciária. Fontainha (2011), ao analisar o concurso da magistratura francesa, mapeia o comportamento geográfico dos candidatos nas diferentes etapas do certame, dividindo-os em sedentários e $n \hat{o}-$ mades. Para além de demonstrar a superioridade da estratégia nômade, viu-se que os padrões de deslocamento geográfico dos candidatos estavam profundamente orientados aos grandes institutos de preparação, mais que à fuga do interior direcionada exclusivamente à Paris. Assim, a necessidade de adequação à configuração institucional republicana das instâncias jurídicas dá a nova tônica das estratégias de deslocamento territorial das elites judiciárias francesas.

Nos Estados Unidos, Greenya (1987) e McGuire (1993a e 1993b) apontam para a centralidade da cidade de Washington, onde se situa a Supreme Court, para a constituição de uma privilegiada instância elitária dentre os juristas americanos. O que muda por lá, ao longo do Século XX, é a sofisticação dos escritórios de advocacia, cada vez mais capilares e capazes de estabelecer relações de solidariedade e parceria com os juristas pertencentes à Washington community. Assim, ser originário daquela cidade ou ter desenvolvido estratégias que compreendam a inserção na sua comunidade jurídica local são fortes predisposições à alçada a posições de elite no Direito norte-americano. Este fenômeno ainda é reforçado pelo baixíssimo deslocamento territorial dos juízes americanos, uma vez que " $3 / 4$ de todos os juízes estaduais nasceu no Estado em que exerce sua jurisdição, e menos de 1/3 saiu do seu Estado para os estudos de graduação" (VIANNA et al: 1997, 137, apud CARP; STIDHAM, 1998: 245).

No Brasil, são Santos e Da Ros que enfrentaram esta mesma temática, com recurso a Carvalho (1980) e Leal (1997). Nas palavras dos próprios autores:

Carreiras mais diversificadas, vinculadas ao estado de origem, com menor mobilidade geográfica, mas também mais breves em sua extensão temporal e com menor fixação em cada um dos cargos intermediários ocupados. $\mathrm{O}$ que essa informação pode indicar acerca das mudanças nos padrões de recrutamento para a cúpula do Judiciário? Mobilidade territorial costuma 
ser interpretada como um processo responsável por reconversão de valores e preferências originais, contribuindo para a formação de elites políticas, sociais, culturais, jurídicas etc., dotadas de coesão e uniformidade (CARVALHO, 1980), reforçando a institucionalização das estruturas capazes de impor custos e barreiras de entrada mais seletivos e rigorosos. A mobilidade territorial da elite imperial, como condição para a ascensão individual nos cargos públicos, e padrões de recrutamento e mobilidade em instituições militares são exemplos do efeito provocado pela circulação geográfica, a qual age como um mecanismo de dissolução de vínculos originais e incorporação de parâmetros institucionais. Se isso é correto, como interpretar as tendências de menor mobilidade geográfica verificadas desde os anos $30 \mathrm{e}$ presentes ainda hoje? Para responder a essa questão, provavelmente seja necessário considerar a expansão institucional do poder Judiciário, com a ampliação de tribunais e da relação juízes/habitantes. À medida em que a estrutura institucional do Judiciário tornou-se mais complexa e dotada de maior cobertura e extensão sobre o território nacional, deve ter ocorrido um aumento na demanda por juízes de primeira instância, tribunais de apelação, tribunais especiais etc., permitindo a progressão de carreiras sem a necessidade do distanciamento geográfico exigido quando essa estrutura era mais rarefeita. Em alguma medida, esse crescimento e burocratização do poder Judiciário, no período posterior a 1930, indicam que tais fatores contribuem, também, para a maior autonomia de seu órgão de cúpula. Em sentido semelhante, pode-se sugerir que esse processo de expansão da estrutura judicial acompanha a tendência do período, em que se consolida a autoridade central ante os grupos locais, os quais passam a ser, em grande medida, dependentes daquela (LEAL, 1997, apud SANTOS; DA ROS, 2008: 144).

Apontando em direção similar ao argumento francês, os autores indicam o fortalecimento de institucionalidades que produziriam a normalização de trajetórias em direção à um percurso geográfico menos errático ou voluntarista.

Estaremos atentos a todas as tendências apontadas, que nos levariam a hipóteses como a centralidade de Brasília e a preponderância das faculdades de Direito e das carreiras formais como elementos predominantes na construção das trajetórias geográficas dos ministros.

No entanto, preferiremos neste artigo uma primeira exploração iterativa dos dados, organizados em torno de categorias e distinções simples. Será relevante para nós cada cidade pela qual cada ministro passou, quanto tempo lá viveu, e o motivo de cada deslocamento. 
Apenas após a construção deste quadro geral, tentaremos organizar estas trinta e três trajetórias analiticamente em torno de alguns padrões de deslocamento territorial, ou tipos de trajetória geográfica.

\section{A coleta e a construção dos dados}

Em primeiro lugar, explanaremos como foi realizada a coleta dos dados que serão apresentados. Conforme já explicado, a principal fonte utilizada foram os roteiros elaborados pela equipe do projeto "História Oral do Supremo"4, para a realização das entrevistas. Uma vez que estes foram produzidos a partir de informações que os próprios ministros disponibilizavam em seus currículos ou em websites, como o DHBB e a Pasta de Ministros do STF, por exemplo, nem sempre eram fornecidos todos os dados necessários para o trabalho de pesquisa. Dessa forma, em alguns casos, foi preciso realizar outras pesquisas adicionais, que pudessem nos fornecer mais informações. Apesar deste retorno às fontes que serviram à elaboração dos roteiros, nem sempre foi possível achar as informações exatas sobre os deslocamentos dos ministros. Nesses casos, informaremos quais foram os métodos utilizados para suprir cada lacuna.

Dito isto, passaremos a descrever como realizamos nossa pesquisa. Iniciamos a compilação dos dados previamente levantados nos roteiros, a partir da elaboração de uma tabela ${ }^{5}$ na qual preenchemos todas as mudanças de cidade ou de país, assinaladas nestes materiais, levando em conta o ano de tais mudanças, assim como as cidades-destino. Ou seja, nas colunas listamos os nomes dos ministros e nas linhas inserimos os anos, que iniciava em 1919, quando dois ministros nasceram (Djaci Falcão e Rafael Mayer), e finalizava no ano da pesquisa.

Deste modo, quando identificássemos uma mudança de cidade ou de país, a partir da leitura dos roteiros, colocávamos no ano correspondente à mudança, assim como indicávamos as razões para tal. Por exemplo: na coluna correspondente ao ministro Djaci Falcão, na linha do ano de 1930, registramos sua mudança foi para Recife/PE, estudar no Colégio Nóbrega.

Por fim, depois da sistematização dos dados na tabela referida acima, desenhamos mapas representando a trajetória geográfica de cada ministro. Além

$<$ www.historiaoraldostf.fgv.br>.

Trata-se de uma tabela de organização e sistematização dos dados previamente levantados nos roteiros, que pudessem indicar as mudanças geográficas dos ministros. Esta tabela teve como objetivo consolidar todos os dados disponíveis nesses materiais, assim como averiguar o que seria possível ser extraído deles. Por representar apenas o início dos nosso trabalho, não será inserida aqui, embora tenha sido essencial para a realização da pesquisa e construção dos demais dados aqui apresentados. 
de mapas individuais, ${ }^{6}$ também foram produzidos outros três mapas, nos quais agrupamos informações sobre o nascimento, local do bacharelado em Direito, e cidade onde estavam quando foram nomeados todos os ministros. O primeiro mostra os locais de nascimento, o segundo, onde cursaram a faculdade de Direito e, por último, onde residiam quando foram nomeados para o Supremo Tribunal Federal. Tais mapas estão inseridos no fim deste artigo (Anexos 1 a 3). Vianna e seus coautores, ao analisar o deslocamento territorial dos magistrados brasileiros, se valeram de variáveis muito próximas às nossas: nascimento, graduação e concurso (VIANNA et al., 1997: 137).

\subsection{Quantificação dos deslocamentos}

Para começar, entendemos relevante estabelecer a quantidade de deslocamentos geográficos realizados por cada ministro. Como se pode perceber por meio da análise do Gráfico 1, a seguir, Francisco Rezek, Eros Grau e Ricardo Lewandoski foram os ministros que mais se deslocaram, tendo dezoito, dezessete e quatorze mudanças, respectivamente. Por outro lado, Marco Aurélio e Rosa Weber deslocaram-se apenas uma vez.

Gráfico 1: Deslocamentos e duração por ministro

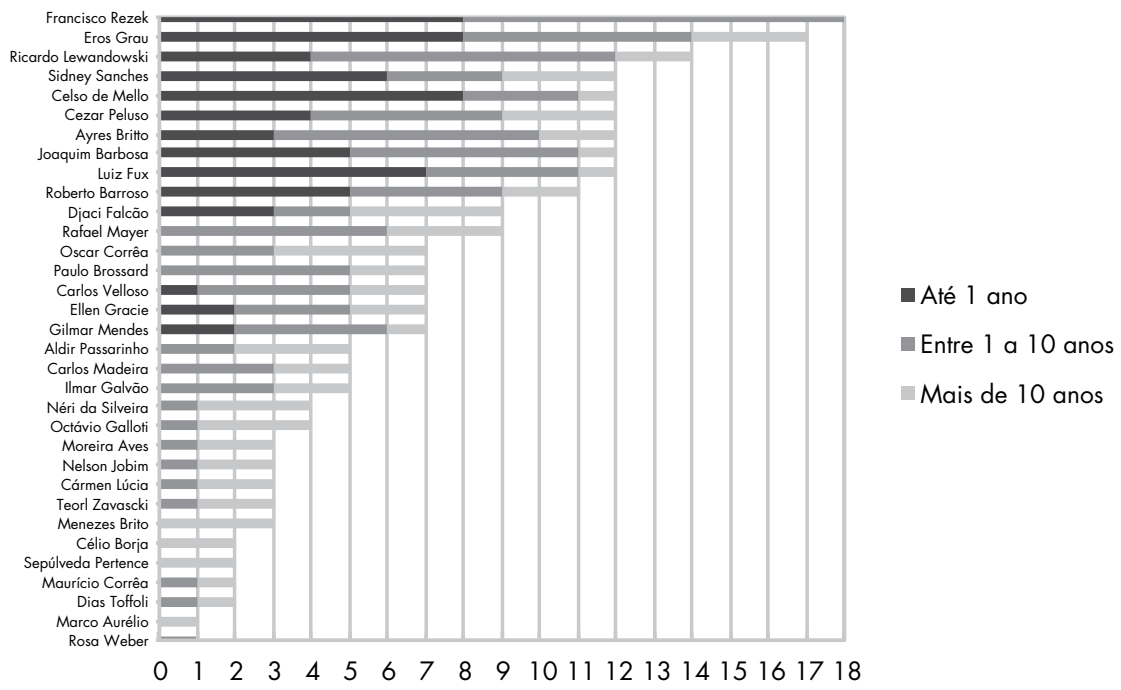

Embora nove, dos trinta e três ministros que fazem parte do nosso universo de pesquisa, ainda estejam na ativa e, portanto, não podemos prever as possíveis

6 Todos os 33 mapas individuais podem ser baixados livremente (DOI: 10.13140/RG.2.2.19599.59045) 
mudanças decorrentes de aposentadoria, percebemos que a aposentadoria dos ministros do STF não tem correlação com o aumento de mudanças de cidade. Ao analisarmos o gráfico anterior, vemos que onze, dos dezesseis ministros que estão abaixo da média de mudanças, já estão aposentados do Supremo. Além disso, dentre os que mais mudaram-se, cinco ainda fazem parte do Supremo.

Ainda por meio da análise do Gráfico 1, temos que a média é de 7,06 mudanças por ministro. Sendo assim, dezesseis ministros encontram-se abaixo desta média. Em contraposição, doze ministros deslocaram-se acima da média. Dessa forma, podem-se classificar os ministros como nômades ou sedentários. Essa questão será abordada mais profundamente ainda neste artigo.

A tabela a seguir exibe quais cidades ou países apareceram mais vezes como destino das mudanças realizadas pelos ministros. Optamos por colocar o país, ao invés da cidade estrangeira porque, conforme explanado anteriormente, as fontes utilizadas nem sempre foram suficientes para encontrar informações precisas. Em alguns casos, os ministros só mencionavam o país de destino. Alguns, no entanto, colocavam as cidades específicas da mudança. ${ }^{7}$ Portanto, para que fosse possível compreender melhor a ida para o exterior, optamos por agrupar esses deslocamentos de acordo com os países de destino.

\section{Tabela X - Destinos}

\begin{tabular}{|l|c|}
\hline \multicolumn{1}{|c|}{ Cidade ou país de destino } & $\begin{array}{c}\text { Quantidade de } \\
\text { notificações }\end{array}$ \\
\hline Brasília/DF & 45 \\
\hline São Paulo/SP & 33 \\
\hline Rio de Janeiro/RJ & 28 \\
\hline Estados Unidos & 12 \\
\hline Porto Alegre/RS & 11 \\
\hline Belo Horizonte/MG & 10 \\
\hline França & 7 \\
\hline Recife/PE & 6 \\
\hline Holanda & 5 \\
\hline São Luís/MA & 4 \\
\hline São Bernardo do Campo/SP & 4 \\
\hline Santos/SP & 4 \\
\hline Santa Maria/RS & 3 \\
\hline
\end{tabular}

7 As cidades-destino no exterior foram: Haia, Paris, Oxford, Washington, Havre, Flórida, Roma, Nova Iorque, Califórnia, Montpellier e Los Angeles. 


(continuação)
\begin{tabular}{|l|c|}
\hline Propiá/SE & 3 \\
\hline Aracaju/SE & 3 \\
\hline Petrópolis/RJ & 2 \\
\hline Paulista/PE & 2 \\
\hline Monteiro/PB & 2 \\
\hline Lorena/SP & 2 \\
\hline Inglaterra & 2 \\
\hline Entre Rio de Minas/MG & 2 \\
\hline Cuiabá/MT & 2 \\
\hline Bagé/RS & 2 \\
\hline Serrita/PE & 2 \\
\hline Alemanha & 2 \\
\hline
\end{tabular}

Outra importante ressalva deve ser feita em relação aos locais que apareceram apenas uma vez. ${ }^{8}$ Estes não foram incluídos na tabela acima, pois entendemos que dificultariam sua análise. Apenas dois países apareceram uma única vez: Bélgica e Itália. Além disso, a maioria das cidades que foram destino dos ministros apenas uma vez são cidades do interior dos estados brasileiros, exceto as capitais estaduais Florianópolis, Natal, Rio Branco, Fortaleza e Belém, que apareceram uma vez apenas.

Passando para a análise da tabela, verificamos que os Estados Unidos figuram como o quarto destino estrangeiro mais popular entre os ministros, uma vez que apareceu doze vezes no total, na frente de cidades como Porto Alegre e Belo Horizonte. Também destacamos as idas à França e à Holanda, que apareceram sete e cinco vezes, respectivamente, menos que à Alemanha e à Itália, sendo que a primeira aparece duas vezes e a segunda apenas uma.

Outro ponto que destacamos é a importância das capitais. Somando a quantidade de vezes que Brasília, São Paulo e Rio de Janeiro apareceram, temos o total de 106 ocorrências dessas cidades. Ou seja, apenas essas três capitais representam $39,84 \%$ do destino dos deslocamentos. A centralidade de

8 Estes foram: Vassouras, Varginha, Triunfo, Trajano de Moraes, Taubaté, Tatuí, São Vicente, São Sebastião, São José dos Campos, São Joaquim do Monte, São João del Rey, São João de Manuçu, São Carlos, São Bento do Sapucaí, Santo André, Santa Maria Madalena, Sabará, Rio Branco, Rincão, Poços de Caldas, Pitangueiras, Pirassununga, Palmital, Pacatu, Osasco, Nova Iguaçu, Niterói, Natal, Montes Claros, Marília, Maraial, Macaé, Lavras do Sul, Jequié, Jaguaquara, Itaúna, Itapeva, Itapetininga, Itália, Iguarassu, Igarapava, Guarulhos, Guararapes, Garça, Gararú, Gameleira, Fortaleza, Florianópolis, Floriano, Finlândia, Faxinal dos Guedes, Espinosa, Diamantino, Cristina, Cordeiro, Chapecó, Caxias, Caruaru, Cantagalo, Cândido Mota, Campinas, Caetano do Sul, Bragança Paulista, Bélgica, Belém, Araraquara e Abre Campo. 
Brasília, que figura como principal destino, é um dado expressivo, uma vez que, dos trinta e três ministros, nenhum nasceu na cidade. Assim como nenhum deles nasceu em São Paulo, capital. Já a cidade do Rio de Janeiro foi local de nascimento de cinco ministros. Em suma, mesmo não sendo cidade natal de nenhum ministro, pode-se argumentar que morar nas cidades de São Paulo e de Brasília, assim como no Rio de Janeiro, é um fator constitutivo da identidade da elite jurídica do Brasil. Os fins de tais deslocamentos serão abordados a seguir.

\subsection{As motivações dos deslocamentos}

Como descrito anteriormente, neste item será tratado a motivação dos deslocamentos dos ministros do Supremo Tribunal Federal. Isto é, por que os ministros se deslocaram? O que os fez mudar de cidade ou de país? Ao investigar atentamente as razões das mudanças, agrupamos esses fenômenos em três categorias: ${ }^{9}$ família, estudos e profissional. Toda vez que algum ministro mudou-se de cidade por motivações pessoais, o que ocorreu, em sua totalidade, por conta do trabalho dos pais dos ministros, esse deslocamento foi classificado como "familiar". Por sua vez, quando mudaram-se para cursar os estudos primários, secundários ou superiores, ou para realizar um curso de curta duração, agrupamos essas mudanças como motivadas pelo "estudo". E, por fim, quando a função profissional desempenhada demandava um deslocamento geográfico, compreendemos que a motivação foi "profissional".

Tendo explicado tais categorias, o gráfico abaixo apresenta a ocorrência de cada motivo para os deslocamentos. $64 \%$ do total das mudanças foi motivada por razões profissionais. Em outras palavras, a maior parte dos ministros mudou-se por causa de seu trabalho. Alguns deles (29\%) também escolheram se deslocar para que pudessem estudar em instituições de ensino localizadas fora da cidade em que se encontravam. Por fim, apenas $7 \%$ do total das mudanças foi realizada por razões familiares. Esses dados podem se tornar ainda mais interessantes quando os relacionamos por ministro. Sendo assim, é possível ver pelo gráfico a seguir, o peso que cada uma das três categorias representa para cada ministro.

9 Ressaltamos que a categorização em relação à motivação dos deslocamentos dos ministros refere-se a uma construção dos pesquisadores, de forma a classificar os deslocamentos e facilitar, assim, a compreensão das trajetórias. 
Gráfico 2: motivações por ministro

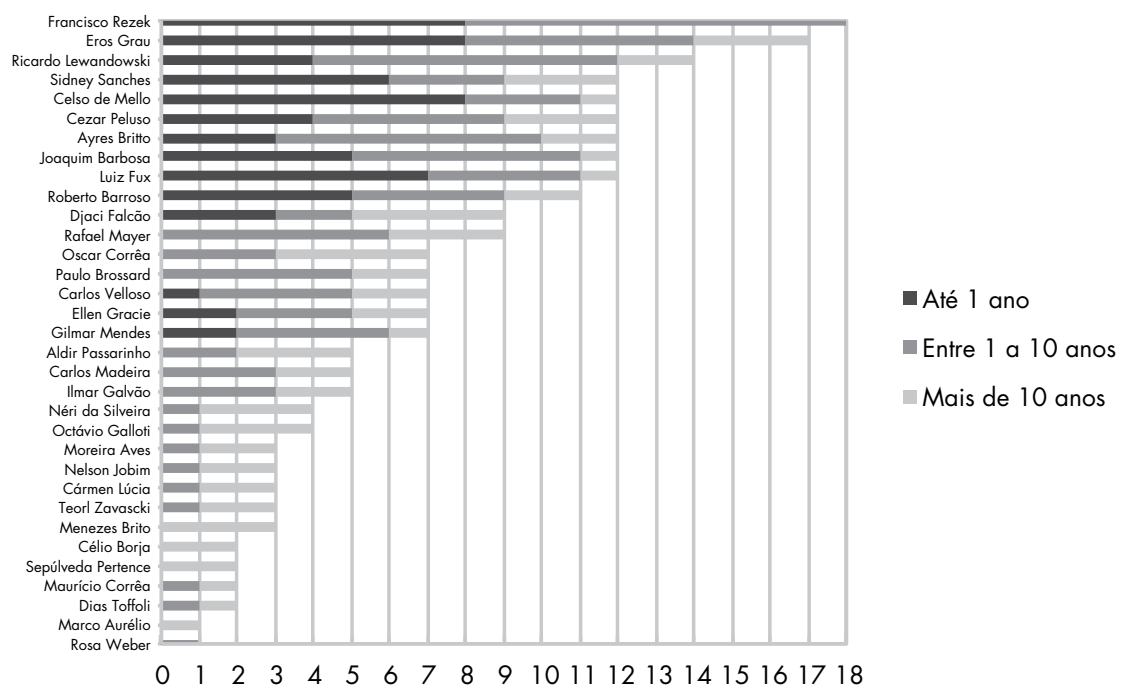

Conforme dito anteriormente, a categoria "profissional" tem uma grande relevância para a ocorrência dos deslocamentos. Ministros como Luiz Fux, Célio Borja, Marco Aurélio e Rosa Weber apenas mudaram de cidade por motivações profissionais. Além disso, dezessete ${ }^{10}$ deles se deslocaram, na maioria das vezes, por motivos de trabalho.

A categoria "estudo" se sobrepôs em alguns momentos à categoria "profissional". Os ministros Teori Zavaski, Ellen Gracie, Carlos Velloso, Gilmar Mendes e Luiz Roberto Barroso mudaram-se mais vezes em decorrência dos estudos do que por razões profissionais. Apenas sete deles ${ }^{11}$ tiveram a mesma quantidade de deslocamentos por ambas as motivações. Por outro lado, oito ${ }^{12}$ deles não se deslocaram nenhuma vez por motivos de estudo. Vale a pena ressaltar que dentre esses oito, somente os ministros Eros Grau, Aldir Passarinho e Moreira Alves não nasceram nas cidades onde cursaram a faculdade de Direito. Eles se mudaram para estas por outras motivações.

Como mostrado anteriormente, motivações familiares são as menos expressivas comparativamente. Dos onze ministros que mudaram de cidade por conta

10 Foram eles: Francisco Resek, Eros Grau, Ricardo Lewandoski, Sidney Sanches, Cezar Peluso, Joaquim Barbosa, Ayres Britto, Celso de Melo, Rafael Mayer, Djaci Falcão, Paulo Brossard, Oscar Corrêa, Ilmar Galvão, Carlos Madeira, Aldir Passarinho, Nelson Jobim e Moreira Alves.

11 Foram eles: Dias Toffoli, Maurício Corrêa, Sepúlveda Pertence, Menezes Direito, Carmen Lúcia, Néri da Silveira e Octavio Gallotti.

12 Foram eles: Eros Grau, Luiz Fux, Carlos Madeira, Aldir Passarinho, Moreira Alves, Célio Borja, Rosa Weber e Marco Aurélio. 
do trabalho do pai, oito ${ }^{13}$ deles o fez uma única vez. Em contraposição a isto, os ministros Ayres Britto e Eros Grau foram os que mais se deslocaram por razões familiares, tendo o feito quatro e três vezes, respectivamente. No entanto, no geral, a motivação familiar não possui tanta relevância se compararmos com as categorias profissional e de estudo.

\subsection{Duração dos deslocamentos}

Também nos pareceu relevante estabelecer a duração de cada deslocamento. Em outras palavras, perguntamos: quanto tempo cada ministro ficou na cidade ou no país para onde deslocou-se?

Na tabela inicial utilizada pela equipe, a quantificação das mudanças foi realizada pelo período de meses. Isto foi necessário tendo em vista que alguns deslocamentos duraram menos de um ano. Todavia, para uma melhor análise, os agrupamos em três categorias: curta duração, média duração e longa duração. ${ }^{14} \mathrm{O}$ primeiro refere-se à permanência de até um ano. A média duração trata de períodos de um ano até dez anos. Por fim, consideramos como mudança de longa duração, aquela na qual o ministro passou mais de dez anos em um mesmo local.

Deste modo, foi possível analisar a duração dessas mudanças e também compará-las entre os próprios ministros. Ou seja, foi possível verificar quem permaneceu mais ou menos tempo em cada local. Ademais, também será possível examinar quais motivações fizeram com que os ministros permanecessem mais tempo nesses destinos.

No gráfico apresentado a seguir, percebe-se uma preponderância dos deslocamentos de média duração, sendo eles $42 \%$ do total das mudanças. Os de longa duração ficam um pouco atrás, com $33 \%$, e os de curta duração têm $25 \%$. Sendo assim, é possível verificar que os ministros, ao se deslocarem muitas vezes, acabaram estabelecendo no local de destino sua moradia permanente. É importante, no entanto, averiguar quais foram as motivações que fizeram com que esses deslocamentos durassem mais ou menos.

É possível conferir quais foram os ministros que mais permaneceram nos locais de destino. Uma primeira inferência que pode ser feita é que entre os

13 Foram eles: Ricardo Lewandoski, Roberto Barroso, Oscar Corrêa, Carlos Madeira, Aldir Passarinho, Moreira Alves, Carmen Lúcia e Menezes Direito.

14 A classificação da duração dos deslocamentos também se deu de modo arbitrário, de acordo com a compreensão dos pesquisadores, e não se refere, portanto, às categorias nativas. Calculamos o tempo de permanência em cada local, contando a data da mudança, quando disponível, até a data da mudança seguinte, e a isso chamamos de "duração". 
ministros que se deslocaram até 5 vezes, nenhum de seus deslocamentos foi de curta duração. Apenas os ministros Paulo Brossard, Oscar Corrêa, e Rafael Mayer estão acima da média e não tiveram nenhum deslocamento de curta duração. Dessa maneira, há uma certa correlação entre ter se mudado abaixo da média e ter se estabelecido mais tempo nos locais de destino.

Ainda sobre os deslocamentos de curta duração, estes estão concentrados no topo do gráfico, ou seja, em sua maioria foram os ministros que mais se deslocaram que tiveram o maior número de mudanças de curta duração. Os ministros Carlos Velloso, Ellen Gracie e Gilmar Mendes também tiveram alguns deslocamentos de curta duração. No entanto, estes ocorreram apenas uma vez para o primeiro e duas vezes para os dois últimos. Sendo assim, os que se moviam mais tendem a ter um maior número de mudanças de até um ano.

Os deslocamentos de longa duração aparecem nos deslocamentos de quase todos os ministros, com exceção de Francisco Rezek e Rosa Weber. O gráfico mostra que mesmo tendo sido praticados pela maioria dos ministros, as mudanças de mais de dez anos aparecem no máximo quatro vezes para dois ministros (Djaci Falcão e Oscar Corrêa).

Passando para o exame do gráfico abaixo, teremos a comparação entre a motivação e a duração das mudanças. Ou seja, temos como conferir quais tipos de deslocamentos levam os ministros a estabelecerem-se por mais tempo no local de destino.

Para começar, nos deslocamentos por motivações profissionais, tem-se que em 60 destes, os ministros ficaram entre 1 e 10 anos. É válido lembrar que não necessariamente os ministros se mantiveram no mesmo emprego, uma vez que isso não seria enquadrado como um deslocamento geográfico. Dessa maneira, o ministro pode ter ido para uma cidade para exercer alguma função e nesta começou a trabalhar em um local diferente, por exemplo. Como será mostrado no Item 3, a maior parte daqueles que por razões profissionais se moveram e ficaram até um ano neste local, exerciam cargos públicos, como juízes e procuradores, por exemplo.

Os deslocamentos por motivos familiares, em sua quase totalidade, eram de média ou longa duração. Destarte, mudar-se em decorrência do trabalho do pai fez com que os ministros se instalassem na cidade de destino e ficassem nesta por um tempo considerável.

Com relação às mudanças motivadas pelo estudo, uma ressalva há de ser feita. Apesar de a maior parte (68,65\%) ter sido de média ou de longa duração, não significa que o ministro necessariamente ficou na cidade ou país de destino 
esse tempo todo estudando apenas. Muitos optaram em continuar morando na cidade onde realizaram seus estudos. Como também será analisado no Item 3 , alguns dentre aqueles que ficaram até um ano na cidade onde foram estudar, em geral, foram para cidades do exterior.

\subsection{Mapas}

Conforme dissemos anteriormente, após a elaboração da tabela de compilação dos dados dos roteiros, para facilitar a visualização das trajetórias geográficas dos ministros e pensarmos a pesquisa, elaboramos os mapas individuais (que podem ser baixados livremente - DOI: 10.13140/ RG 2.2.19599.59045) e também agrupamos algumas variáveis, desenhando mapas contendo informações de todos os ministros. Os mapas que contém informações de todos são três. O primeiro (Anexo 1) mostra os locais de nascimento dos ministros. Como é possível perceber, apenas oito ministros nasceram em capitais brasileiras. A maior parte deles nasceu no interior. Conforme veremos no próximo mapa sobre o local do bacharelado em Direito, há um nítido deslocamento para as capitais.

No mapa sobre o bacharelado em Direito (Anexo 2), pode-se visualizar a cidade onde os ministros realizaram seus estudos superiores. Apenas um ministro (Cezar Peluso) estudou em uma cidade do interior (Santos/SP). Todos os outros 32 ministros cursaram Direito em capitais, lembrando que apenas oito nasceram nestas. Dessa maneira, estudar Direito nas capitais, principalmente nas do Sudeste e em Porto Alegre, é traço marcante do grupo estudado. Ademais, percebemos que, embora nenhum ministros tenha nascido na Capital Federal, dois deles cursaram Direito em Brasília.

Elaboramos também um mapa que indica onde os ministros estavam desempenhando a principal atividade profissional quando foram nomeados para o Supremo Tribunal Federal (Anexo 3). Notamos que, mesmo que nenhum ministro tenha nascido em Brasília, e que somente dois tenham cursado o bacharelado lá, vinte e três deles já se encontravam na cidade quando foram nomeados para o STF. Portanto, verificamos o que chamamos de "centralidade de Brasília" na trajetória geográfica dos ministros, isto é, o papel da cidade como centro das profissões jurídicas vinculadas às carreiras públicas em relação a outras cidades do país. Também podemos afirmar que atuar no sudeste do país teve alguma relevância para a nomeação dos ministros, já que dentre os dez ministros que não estavam em Brasília, sete deles encontravam-se em capitais do sudeste. 


\section{Tipos de deslocamento}

Depois de feito todo o levantamento acima descrito, desenhados os mapas e compilados os dados, verificamos que algumas trajetórias podem ser organizadas analiticamente a partir de suas sincronicidades e diacronicidades. Com isso, passaremos a tipificar (Weber, 1949) as trajetórias geográficas desses ministros, não no sentido do trabalho que aponta os "caminhos profissionais e políticos que levam à corte", ou seja, o que leva à nomeação (SANTOS; DA ROS, 2008), mas de acordo com o que essas trajetórias trazem, geograficamente, de comum.

Assim, agrupamos as trajetórias geográficas dos ministros em 3 tipos ideais, que podem ser assim descritos: (1) carreiras construídas e vidas estabelecidas diretamente em Brasília; (2) carreiras e vidas estabelecidas fora de Brasília e cuja ida para a Capital Federal se deu somente quando da nomeação para o Supremo Tribunal Federal; (3) vidas estabelecidas entre Brasília e outra cidade, sendo difícil precisar qual cidade teria mais peso na trajetória do ministro. Todas as trajetórias podem ser de tipo (a) nômade ou (b) sedentária, isto é, passando por muitas mudanças de cidade ou por poucas mudanças. Para a construção dessa última categoria analítica levamos em conta a média de mudanças citada na seção anterior - 7 por ministro - situando entre os nômades aqueles que se mudaram 7 vezes ou mais. A frequência foi, portanto, nossa variável fundamental para esta categorização.

Além disso, ao organizarmos nossos dados, percebemos duas expressões interessantes nas trajetórias geográficas que merecem destaque no presente trabalho, embora não pareçam estruturantes para a nossa questão central. A primeira, quanto aos ministros que desempenharam cargos públicos cujo exercício os obrigava a viajar pelo interior dos estados brasileiros, que chamamos de "nômades institucionais". A segunda, que chamamos de "nomadismo internacional", referente às estadias internacionais que marcam as vidas de alguns ministros. Tais traços serão tratados ao final do texto, embora sejam mencionados ao longo do texto.

Importa destacar que, obviamente, não descreveremos as trajetórias desses ministros de forma a esgotar cada uma em suas complexidades, face ao tipo de pesquisa que nos propusemos, mas tentaremos sempre mostrar suas especificidades, quando os dados estiverem ao nosso alcance. A tabela a seguir sistematiza nosso esforço tipológico. 
Tabela 2 - Tipos de trajetória

\begin{tabular}{|c|c|c|c|c|}
\hline & Sedentários & Nômades & $\begin{array}{l}\text { Nômades } \\
\text { Institucionais }\end{array}$ & $\begin{array}{l}\text { Nômades } \\
\text { Internacionais }\end{array}$ \\
\hline Brasilienses & $\begin{array}{l}\text { Sepúlveda Pertence; } \\
\text { Maurício Correa; } \\
\text { Dias Toffoli }\end{array}$ & & & $\begin{array}{l}\text { Joaquim Barbo- } \\
\text { sa; Gilmar Men- } \\
\text { des; Francisco } \\
\text { Rezek }\end{array}$ \\
\hline Não brasilienses & Carmem Lúcia & $\begin{array}{l}\text { Oscar Corrêa; } \\
\text { Ayres Britto }\end{array}$ & $\begin{array}{l}\text { Djaci Falcão; } \\
\text { Cézar Peluso; } \\
\text { Sidney Sanches }\end{array}$ & $\begin{array}{l}\text { Ellen Gracie; } \\
\text { Ricardo Lewan- } \\
\text { dowski; Eros } \\
\text { Grau }\end{array}$ \\
\hline Semi brasilienses & $\begin{array}{l}\text { Menezes Direito; Teori } \\
\text { Zavascki; Néri da Sil- } \\
\text { veira; Rosa Weber; } \\
\text { Marco Aurélio; } \\
\text { Nelson Jobim; Octávio } \\
\text { Galloti; Célio Borja; } \\
\text { Moreira Alves; Carlos } \\
\text { Madeira; Aldir Passa- } \\
\text { rinho; Ilmar Galvão. }\end{array}$ & $\begin{array}{l}\text { Carlos Velloso; } \\
\text { Paulo Brossard }\end{array}$ & $\begin{array}{l}\text { Luiz Fux; } \\
\text { Rafael Mayer }\end{array}$ & $\begin{array}{l}\text { Celso de Mello; } \\
\text { Roberto Bar- } \\
\text { roso; }\end{array}$ \\
\hline
\end{tabular}

\subsection{Brasilienses}

Agrupamos nesta categoria analítica os ministros que construíram suas carreiras profissionais na cidade de Brasília, tendo, necessariamente, vivido previamente em outras cidades, mas fixando-se por mais tempo, e de forma mais intensa, na capital federal. Dividimos todos os tipos entre sedentários e nômades, sendo os primeiros aqueles que mudaram menos vezes de cidade e separamos no segundo subgrupo aqueles que se transferiram mais vezes, passando por outras cidades.

\subsubsection{Brasilienses Sedentários}

O traço comum dessas trajetórias é o fato de terem como ponto culminante em suas carreiras a mudança para a capital federal, onde exerceram diversas funções, até suas nomeações para o STF, consolidando laços de relação profissional e pessoal na cidade, sendo Brasília o lugar onde permaneceram por mais tempo, ainda antes de sua nomeação.

\subsubsection{Brasilienses Nômades}

Os três ministros cujas trajetórias tratamos nesse tipo, têm em comum o fato de terem vivido a maior parte de suas vidas em Brasília, onde estabeleceram laços profissionais e pessoais antes de suas nomeações para os cargos de 
ministro. Além disso, os três podem ser inseridos no "nomadismo internacional", uma vez que todos tiveram passagens internacionais, embora, claro, Francisco Rezek seja aquele que viveu por mais tempo no exterior.

\subsection{Não brasilienses}

Neste tipo, agrupamos os ministros que viveram a maior parte de suas vidas fora de Brasília, mudando para a capital federal somente quando de sua nomeação, sem que antes tivessem vivido na cidade. $O$ que chama atenção - e é o traço em comum que se destaca entre eles - é o fato de as construções de suas carreiras profissionais e laços pessoais terem se dado em outras partes do país e não na capital federal.

\subsubsection{Não brasilienses sedentários}

A ministra Carmen Lúcia nasceu no interior de Minas Gerais, na cidade de Montes Claros, viveu com seu pai em Espinosa/MG e mudou-se para Belo Horizonte, onde cursou os estudos secundários e a universidade. Após o seu bacharelado, passou a atuar profissionalmente na cidade, saiu de Belo Horizonte para cursar seu doutorado, em São Paulo, finalizado no ano de 1983, quando voltou para Belo Horizonte para atuar como professora e, posteriormente, como Procuradora do Estado, progredindo na carreira até tornar-se Procuradora Geral. Mudou-se para Brasília no ano de 2006, para a sua posse no Supremo Tribunal Federal. Esse tipo ideal consiste numa trajetória direta, após a construção de laços e vínculos mais longos em uma cidade, com a mudança para a capital federal para a nomeação como ministra.

\subsubsection{Não brasilienses nômades}

Este tipo ideal caracteriza-se pela construção de vínculos profissionais fora da cidade de Brasília, passando por diversas mudanças ao longo da vida dos ministros e transferindo residência para Brasília somente quando da nomeação para o STF. O nomadismo aqui pode ser tanto institucional, quando o ministro mudou-se para o desempenho das suas funções profissionais, como é o caso de Sidney Sanches e Cézar Peluso, quanto contar com períodos internacionais, como no caso de Eros Grau e Ricardo Lewandowski.

\subsection{Semi brasilienses}

Agrupamos nesta categoria analítica - subdividida entre nômades e sedentários - os ministros que apresentam sua trajetória marcada pelo tempo 
passado em Brasília, embora esta pertença não seja tão marcante, dada a existência de outras cidades relevantes em suas trajetórias.

\subsubsection{Semi brasilienses sedentários}

As trajetórias desse grupo caracterizam-se pela proeminência de outra cidade, além de Brasília, na construção de suas vidas. Nos casos citados há pouco, é difícil delimitar qual cidade pode ter sido mais importante para a construção profissional que culminou na nomeação como ministro do Supremo, uma vez que os lugares onde viveram anteriormente também foram relevantes nas suas atuações profissionais. Exemplo disso é a trajetória de Nelson Jobim que, embora tenha vivido mais tempo em Brasília, sua ida para a capital federal como deputado está diretamente ligada aos laços estabelecidos no Rio Grande do Sul, assim como Célio Borja, eleito pelo estado do Rio de Janeiro. Além disso, consideramos que a qualidade da experiência precisa ser contraposta ao tempo de permanência no local, uma vez que todas as experiências profissionais em Brasília, antes da nomeação no STF, foram em cargos relevantes como Ministros de Estado, ministros de outros Tribunais Superiores ou, ainda, exercendo mandatos no legislativo.

Os ministros que desempenharam funções nos Tribunais Superiores foram Rosa Weber e Marco Aurélio no Tribunal Superior do Trabalho; Néri da Silveira, Carlos Alberto Madeira e Aldir Passarinho, no Tribunal Federal de Recursos; Teori Zavascki e Menezes Direito, no Superior Tribunal de Justiça. Por fim, as demais experiências em Brasília foram em cargos de relevância, como Octávio Galloti no Tribunal de Contas da União, Moreira Alves como Procurador Geral da República. Essas experiências, embora mais curtas que aquelas vividas nas cidades anteriores, pela sua intensidade foram de grande importância em suas trajetórias.

\subsubsection{Semi brasilienses nômades}

Neste tipo destaca-se a intensidade das experiências em Brasília, sendo difícil especificar se as experiências anteriores foram mais relevantes em suas carreiras, considerando as funções desempenhadas em Brasília: ministro do STJ, no caso de Luiz Fux; Ministro do TFR, no caso de Carlos Velloso; Senador e Ministro da Justiça, no caso de Paulo Brossard; e Consultor-Geral da República, no caso de Rafael Mayer. Destacamos, ainda, a existência de dois casos de "nomadismo internacional": Roberto Barroso e Celso de Mello, e um caso de "nomadismo institucional": Luiz Fux. 


\subsection{Nomadismo Institucional}

Este grupo de ministros tem em comum o exercício de funções no poder Judiciário que demandam um período de atuação no interior, seja porque foram juízes ou porque foram promotores de justiça, todos viveram ou atuaram profissionalmente em comarcas do interior dos estados em razão dos cargos que desempenhavam. Deles, somente Luiz Fux nasceu em uma capital, na cidade do Rio de Janeiro, e somente Cezar Peluso estudou Direito fora das capitais, uma vez que obteve o grau de bacharel em Direito na cidade de Santos/SP. Para a realização de nossa pesquisa, presumimos como local de residência a cidade onde foram lotados para o exercício das funções.

Esse grupo apresenta uma dimensão relevante da trajetória geográfica de juristas no Brasil que, ao desempenharem funções no Judiciário, são designados para comarcas no interior dos estados, passando por diversas cidades até serem lotados na capital. Consideramos que em alguma medida, e de alguma forma, essa experiência marca suas trajetórias e vidas.

\subsection{Nomadismo Internacional}

Neste grupo, reunimos os ministros que tiveram experiências no exterior e as separamos entre "estadias curtas" - menores ou de até um ano - e "estadias longas" - que se deram por mais de um ano. Nas estadias curtas, estão a Ministra Ellen Gracie e os ministros Luis Roberto Barroso, Eros Roberto Grau e Ricardo Lewandowski. Entre os ministros que viveram fora do país por mais de um ano, temos Celso de Mello, Joaquim Barbosa, Gilmar Mendes e Francisco Rezek, que permaneceram no exterior tanto para a realização de estudos secundários, mestrado ou doutorado, como é o caso de Celso de Mello, Joaquim Barbosa e Gilmar Mendes, quanto para o desempenho de funções profissionais, como é o caso de Francisco Rezek.

Assim, inserimos neste grupo os ministros que viveram experiências internacionais ao longo de suas trajetórias, sendo importante separar aqueles que permaneceram por períodos mais longos, caracterizando um tempo maior longe do Brasil, inseridos em outros contextos internacionais. Apenas Eros Grau e Francisco Rezek estiveram fora do país também para o desempenho de funções profissionais, não apenas para viagens acadêmicas; o primeiro para a Corte Internacional de Arbitragem, na França, e o segundo para a Corte Internacional de Justiça. A maior parte das viagens desses ministros deu-se, portanto, para "estudo" e desempenho de funções acadêmicas. 


\section{Consideracõos finais}

Este artigo compõe uma série de estudos ainda a ser publicada. Em outros artigos serão tratadas as trajetórias acadêmica, política, jurídica, as origens sociais e a notoriedade sociocultural. $\mathrm{O}$ que se pretende agora é adiantar alguns argumentos que sintetizam parcial e provisoriamente os resultados da pesquisa relativa ao deslocamento territorial dos ministros do STF de 1988 a 2013.

Inicialmente, verificou-se, a despeito de origens sociais altas ou médias, uma predominância de naturalidades fora de capitais. Scheman, em sua pesquisa sobre as origens sociais e econômicas dos magistrados brasileiros de meados do século passado, chega a resultados parecidos:

To a pronounced degree, the magistrature as a career was more attractive to young men born in the interior of the state, as distinguished from the capital cities. $75 \%$ of those responding indicated origins in the interior of the states, a pattern consistent for all geographic regions (...). Although the $25 \%$ who came from capital cities exceeds the $18 \%$ figure of the overall Brazilian population 5 residing in the capitals, such a comparison is unreliable due to the fact that secondary and superior education is far more accessible to those in the capital cities. In the years that these judges attended law school, for example, 96\% of the law schools were located in the capital cities, where even today $65 \%$ of the law schools are found. (SCHEMAN: 1962, 49).

Como pudemos ver, não são apenas os estudos que atuam como agentes do deslocamento territorial, em particular naquela focada no movimento interior-capital. Independentemente da causa do deslocamento, podemos afirmar que tanto para nômades quanto para sedentários, origem e destino revelam momentos decisivos nas suas trajetórias.

Para nômades, sejam internacionais ou institucionais, podemos atribuir ao próprio nomadismo um fator de legitimação, agregando à biografia uma trajetória "clássica" no seio de uma instituição do sistema de justiça, ou uma trajetória de "excelência" com a passagem por instituições de ensino jurídico internacional. Além disso, em ambos os casos, o simples esforço adaptativo pode ter estimulado o desenvolvimento de habilidades e competências extremamente valiosas no mundo do Direito. $\mathrm{O}$ enfrentamento de novos quadros interativos e dialógicos sucessivamente, além de permitir o refinamento da sociabilidade, amplia consideravelmente a rede pessoal e profissional.

Para sedentários, o que fica claro é a ancoragem local, vindo sua legitimidade justamente dos quadros relacionais construídos ou no seu território de 
origem ou diretamente em Brasília. Ainda que em alguns casos esta ancoragem não tenha servido diretamente à alçada a Ministro do Supremo, no caso dos sedentários "semi-brasilienses", por exemplo, é difícil delimitar qual cidade teve maior importância na sua trajetória, ou seja, tanto a cidade de origem quanto Brasília impactaram tal construção. Em todos os casos que chamamos de "sendentários", é certo que a ancoragem local teve um peso forte na construção da ocupação da primeira posição elitária na hierarquia ocupacional do Direito.

Um segundo aspecto a ser tomado em conta nestas conclusões parciais, considerando a origem predominantemente periférica dos ministros, concerne os centros para onde se realiza seu deslocamento. Apesar de uma considerável notificação das cidades de São Paulo e do Rio de Janeiro, bem como de alguns destinos internacionais, é na capital federal que devemos concentrar mais atenção.

Poderia-se argumentar que a super-notificação de Brasília no nosso levantamento se deve ao simples fato de que o STF lá tem sua sede, considerado nosso recorte temporal e a população que se pretende biografar coletivamente. Seria, sim, uma conclusão evidente não fosse o seguinte dado: dois terços dos ministros já se encontravam em Brasília no momento da sua nomeação.

Como já vimos, Brasília concentra as sedes de várias instituições de elite da política e do Direito: o Congresso Nacional, o Ministério da Justiça, a Advocacia Geral da União, a Procuradoria Geral da República, o Superior Tribunal de Justiça etc. Assim, para grande maioria dos ministros, Brasília significou um destino essencial no processo de legitimação que permitiu a alçada ao STF.

Nem todos os Ministros de outros Tribunais Superiores, Advogados Gerais da União, Procuradores Gerais da República e Ministros da Justiça são alçados ao Supremo. Uma minoria deles o é. Desta forma, seria errado afirmar que existem posições periféricas e condicionantes do cargo de Ministro do STF. No entanto, o tempo e a posição ocupada em Brasília implicam em reflexões mais profundas.

Werneck Vianna e seus coautores, ao examinar os padrões de deslocamento territorial dos magistrados brasileiros, desenvolvem o seguinte argumento:

A atual mobilidade espacial do juiz brasileiro parece confirmar um antigo traço da cultura jurídico-política do país, para o qual os ideais do Direito e da justiça deveriam proceder de um centro dissociado do poder local, uma vez que neste último se expressaria a tradição de prepotência, de mandonismo e de dependência pessoal presentes nas raízes da formação nacional. O "desenraizamento" seria, então, funcional a um desempenho do Judiciário imune ao localismo e ao paroquialismo e, nas circunstâncias de hoje, 
tendencialmente propício à sua adesão ao constitucionalismo democrático (VIANNA et al: 1997, 136). ${ }^{15}$

Os autores sugerem um padrão de deslocamento que acompanha os movimentos de profissionalização e racionalização já descritos na introdução deste artigo. Este movimento teria a consequência política e social de "desenraizar" o magistrado dos seus laços locais de origem, permitindo a criação de centros onde se poderia desenvolver uma ideologia propriamente republicana. Ao nosso ver, por se tratar de uma pesquisa sobre magistrados de carreira, burocrática e quase uniformemente organizados, uma dimensão pode ter escapado aos autores.

Porque o mandonismo, a dependência pessoal, o localismo e o paroquialismo não poderiam se reproduzir no centro? Para além, por que todos estes atributos, relacionados comumente à tradição brasileira, não poderiam estar amplificados, em particular num centro de impossível enraizamento de origem (ao menos para esta geração), como Brasília?

Relembramos que o Supremo não é o cume da hierarquia judiciária, apenas da hierarquia jurisdicional. O que vale para os recursos, não vale para os magistrados. No STF o acesso é direto e se faz por indicação política, e se trata de um tribunal que congrega elites jurídicas, não necessariamente elites originariamente judiciárias.

Assim, ao contrário do que sugerem Werneck Vianna e seus coautores (1997), nossos dados indicam a existência de forte padrão de "reenraizamento" brasiliense como marcador predominante nos ministros do STF, e talvez como expressão de capacidade reprodutiva das relações de poder que organizam este novo local.

O que se deve levar em conta é que este "reenraizamento", compreendido como esforço de adaptação a novos quadros dialógicos e interacionais cotidianos - que apenas ao longo de um processo de socialização fazem erigir uma nova ideologia -, é mais fortemente impulsionado pela inexistência de elites tradicionais brasilienses.

Brasília é, assim, além de um excelente acelerador social - ao menos nas hierarquias ocupacionais políticas e jurídicas - também uma das mais claras evidências empíricas das complexas relações entre a política e o Direito.

Outro aspecto que merece reflexão diz respeito a um "silêncio" dos nossos dados: a perseguição política como variável essencial do deslocamento geográfico. Além das variáveis que foram amplamente reparadas por nós, como agentes causais (família, estudos, trabalho), a ampla literatura - em especial da área

15 Os autores fazem menção, neste parágrafo, às ideias de Vianna (1973) e Vieira (1994: 144), respectivamente. 
de geografia - também destaca razões ligadas a contextos políticos específicos como fatores migratórios primordiais. ${ }^{16}$

Nos dados que pudemos obter, nenhum dos componentes do grupo que biografamos apresentou notificação de deslocamento territorial atrelada à esta causa. Este "silêncio" dos nossos dados reforça dois eixos de hipóteses formuladas sobre as elites judiciais brasileiras, em particular durante o período autoritário iniciado em 1964. A primeira delas é a de que os juristas foram efetivamente um grupo social menos engajado em movimentos de oposição ao regime autoritário instaurado com o golpe de 1964. A segunda é a de que membros das elites jurídicas eventualmente envolvidos em movimentos oposicionistas gozaram de uma maior proteção e tolerância por parte do regime.

Por fim, um último aspecto a ser explorado concerne um padrão de deslocamento que une os destinos no exterior aos estudos de pós-graduação. Dois extremos da construção de um padrão podem ser reivindicados. De um lado, poderíamos dizer que se trata de um esforço objetivo visando agregar à biografia um importante marcador social comumente associado ao notório saber jurídico. A obtenção de diploma acadêmico no exterior constituiria forte ferramenta de empoderamento elitário e importante gatilho para a nomeação ao STF. O caráter instrumental desta estratégia seria demonstrado pela predominância de deslocamentos de curta duração quando o destino é o exterior e o motivo são estudos.

Por outro lado, se poderia argumentar que a capacidade de reproduzir o pensamento jurídico de outras tradições social e simbolicamente valorizadas (como a americana, a francesa, a holandesa e a alemã) constitui atributos individuais absolutamente distintivos na atuação cotidiana de um "supremável". Para além disso, ser presumivelmente alguém cuja rede de relações profissionais ultrapassa as fronteiras nacionais também seria forte traço de pertença à elite.

Krisnan e seus coautores recentemente argumentaram pela influência da vinda ao Brasil de advogados norte-americanos na remodelagem da nossa advocacia corporativa (2015: 45), com base em estudos previamente realizados sobre a influência dos Estados Unidos no Direito latino-americano a partir dos anos sessenta (DEZALAY; GARTH, 2002: 11; 2010, TRUBEK, 2011). Além destes autores, outros argumentam pela porosidade do Direito brasileiro a movimentos de aculturação (e não internacionalização), e a busca por formações e diplomas jurídicos estrangeiros seria uma das maiores expressões desta tendência.

O apego ao Direito pátrio, e ao vernáculo que o exprime, seria uma marca de pertença ao mundo do Direito. No entanto, uma trajetória adornada por

16 Ver a este respeito: VAINER: 1996 e 2001, OLIVEIRA: 2011, FERNANDES: 2012, e JUBILUT; MADUREIRA: 2014. 
diplomas estrangeiros, mas também pela capacidade de reprodução de suas teorias e preceitos jurídicos - quiçá em língua estrangeira - seria uma forte marca de pertença às elites do Direito.

\section{Referências}

BOIGEOL, Anne. La formation des magistrats : de l'apprentissage sur le tas à l'école professionnelle. Actes de la recherche en sciences sociales, Vol. 76, No. 1, 1989.

CARP, Robert; STIDHAM, Ronald. Judicial Process in America. Los Angeles: CQ Press, 1998.

CARVALHO, José Murilo de. A construção da ordem: a elite política imperial. Rio de Janeiro: Campus, 1980.

CHARLE, Christophe. Pour une histoire sociale des professions juridiques à l'époque contemporaine : note pour une recherche. Actes de la recherche en sciences sociales, Vol. 76, No. 1, 1989 .

État et magistrats : Les origines d'une crise prolongée. Actes de la recherche en sciences sociales, Vol. 96, No. 1, 1993.

DEZALAY, Yves; GARTH, Bryant. The Internationalization of Palace Wars: Lawyers, Economists and the Contest to Transform Latin American States. Chicago: The University of Chicago Press, 2002.

Asian Legal Revivals: Lawyers in the Shadow of Empire. Chicago: The University of Chicago Press, 2010.

FERNANDES, Pádua. Migração na ditadura militar brasileira: desejados e indesejados perante a doutrina de segurança nacional. In: Segundo Congreso de la Sociedad Latinoamericana para el Derecho Internacional, Rio de Janeiro, 23 a 25 de agosto 2012.

FONTAINHA, Fernando. Les (en)jeux du concours: un étude interactionniste du recrutement à l'École de la Magistrature française. Sarrebrück: Éditions Universitaires Européennes, 2011.

GREENYA, John. Supreme Lawyers. Washington Lawyer, Maio-Junho: p. 34-45, 1987.

JUBILUT, Liliana Lyra; MADUREIRA, André de Lima. Os desafios de proteção aos refugiados e migrantes forçados no marco de Cartagena+30. REMHU - Revista Interdisciplinar de Mobilidade Humana, Brasília, Ano XXII, n. 43, p. 11-33, jul./dez. 2014.

KRISNAN, Jayanth; DIAS, Vitor; PENCE, John. Legal Elites and the Shaping of Corporate Law Practice in Brazil: A Historical Study. Law \& Social Inquiry, (forthcoming) 2015.

LEAL, Victor Nunes. Coronelismo, enxada e voto: o município e o regime representativo no Brasil. Rio de Janeiro: Nova Fronteira, 1997.

MCGUIRE, Kevin. The Supreme Court Bar: Legal Elites in the Washington Community. Charlottesville: University Press of Virginia, 1993a. 
. Lawyers and the U.S. Supreme Court: The Washington Community and Legal Elites. American Journal of Political Science. Vol. 37, No. 2, 1993 b.

OLIVEIRA, Antônio Tadeu Ribeiro de. Algumas abordagens teóricas a respeito do fenômeno migratório. In: OLIVEIRA, Luiz Antonio Pinto de; OLIVEIRA, Antônio Tadeu Ribeiro de (Orgs.). Reflexões sobre os Deslocamentos Populacionais no Brasil. Rio de Janeiro: IBGE, 2011.

SANTOS, André Marenco dos; DA ROS, Luciano. Caminhos que levam à Corte. Revista de sociologia e política. v. 16, n. 30, p. 131-149, 2008.

SCHEMAN, Ronald. The social and economic origins of the Brazilian judges. InterAmerican Law Review. V. 4 N. 45, 1962.

ROYER, Jean-Pierre. Histoire de la Justice en France. Paris: PUF, 2001.

TRUBEK, David. Reforming Legal Education in Brazil: From the Ceped Experiment to the Law Schools at the Getulio Vargas Foundation. University of Wisconsin Legal Studies Research Paper, n. 1180, 2011.

VAINER, Carlos B. Deslocados, reassentados, clandestinos, exilados, refugiados, indocumentados: as novas categorias de uma sociologia dos deslocamentos compulsórios e das restrições migratórias. In: CASTRO, Mary Garcia (Org.). Migrações internacionais: Contribuições para políticas. Brasília: CNPD, 2001.

A violência como fator migratório: silêncios teóricos e evidências históricas. In: Revista Travessia, ano IX, n. 25, maio-agosto de 1996.

VIANNA, Oliveira. Populações meridionais do Brasil. Rio de Janeiro: Paz e Terra, 1973.

VIANNA, Luiz Werneck; CARVALHO, Maria Alice Rezende de. MELO, Manuel Palácios Cunha. BURGOS, Marcelo Baumann. Corpo e Alma da Magistratura Brasileira. Rio de Janeiro: Revan, 1997.

VIEIRA, Oscar Vilhena. Supremo Tribunal Federal - Jurisprudência Política. São Paulo: Editora Revista dos Tribunais, 1994.

WEBER, Max. The Methodology of the social sciences. The Free Press: Illinois, 1949.

Recebido em 20/02/2017

Aprovado em 01/05/2017

\section{Como citar este artigo:}

FONTAINHA, Fernando de Castro ; NUÑEZ, Izabel; OTERO, Verônica Beviláqua. O lugar das elites jurídicas: o deslocamento territorial dos ministros do STF (19882013). Contemporânea - Revista de Sociologia da UFSCar, v. 7, n. 2, jul.- dez. 2017, pp. 341-364. 